\title{
O ensino de história da África na formação continuada de professores/as da educação básica: temas e encaminhamentos pedagógicos
}

\author{
The teaching of history of Africa in the continuing formation of teachers \\ basic education: themes and pedagogical guidelines
}

\author{
Di Delton Aparecido Felipe \\ Doutor em Educação \\ Universidade Estadual de Maringá - UEM. \\ Maringá, Paraná - Brasil. \\ ddelton@gmail.com
}

Resumo: O presente artigo tem como objetivo discutir estratégias para formação docente para o ensino da História da África. Para isso relatamos os resultados de um curso de extensão intitulado Ações de promoção à formação de professoras e professores para o ensino de história e cultura afro-brasileira na Educação Básica e, para melhor atender ao nosso intuito, priorizamos analisar as informações coletados em um dos encontros, que teve como tema a 'História da África e do povo negro no Brasil'. No decorrer da formação fizemos um esforço para apontar estratégias que os docentes podem adotar para trabalhar com a História da África nas diferentes disciplinas escolares e concluímos que os conhecimentos oriundos dos povos africanos são cruciais para explicar os múltiplos saberes presentes no Brasil e construir uma educação antirracista.

Palavras chave: formação de professores/as; história da África; educação antirracista.

Abstract: This article aims to discuss strategies for teacher training for teaching the history of Africa. For this we report the results of an extension course entitled Actions to promote the formation of teachers for the teaching of Afro-Brazilian history and culture in Basic Education and, to better meet our purpose, we prioritize analyzing the information collected in one of the meetings, which had as its theme the 'History of Africa and the black people in Brazil'. During the course of the training we made an effort to point out strategies that teachers can adopt to work with the History of Africa in the different school disciplines and We conclude that knowledge from African peoples is crucial to explain the multiple knowledge present in Brazil and to build an anti-racist education.

Key-words: teacher education; history of Africa; anti-racist education.

Cite como

(ABNT NBR 6023:2018)

FELIPE, Delton Aparecido. O ensino de história da África na formação continuada de professores/as da educação básica: temas e encaminhamentos pedagógicos. Dialogia, São Paulo, n. 39, p. 1-16, e20219, set./dez. $2021 . \quad$ Disponível em: https://doi.org/10.5585/39.2021.20219.

American Psychological Association (APA)

Felipe, D. A. (2021, set./dez.) O ensino de história da África na formação continuada de professores/as da educação básica: temas e encaminhamentos pedagógicos. Dialogia, São Paulo, 39, p. 1-16, e20219. https://doi.org/10.5585/39.2021.20219. 


\section{Introdução}

A obrigatoriedade do ensino de História e Cultura Afro-brasileira e Africana na Educação Básica foi outorgada em 09 de janeiro 2003 pelo o Conselho Nacional de Educação (CNE), por meio da Lei Federal 10.639. A aprovação dessa lei faz parte da luta antirracista empreendida pelo movimento negro brasileiro desde fins da década de 1970, como uma estratégia de questionamento do discurso de que no Brasil não havia racismo, como pregava o mito da democracia racial, perpetuado desde a década de 1930 por pensadores como Gilberto Freire (1900 - 1987), Sergio Buarque de Holanda (1902-1982) e Roger Bastide (1898 - 1974), que tinha o intuito de propagar uma identidade nacional mestiça e harmônica.

Dentro de uma perspectiva antirracista, o movimento negro, em especial a partir das últimas décadas do século XX, preocupou-se em elaborar políticas de valorização da população negra. Um exemplo dessas ações, como relata Munanga (2001), foi uma campanha intitulada ' $O$ negro é lindo' baseada no movimento norte americano 'black is beautiful', pela qual o termo negro deixou de ser considerado ofensivo, como acontecia antes, e passou a ser empregado com orgulho pelos ativistas. A campanha também permitiu ressaltar as características estéticas, históricas e socias da população afrodiaspóricas no território nacional. Ações do movimento negro, a partir do final da década 1970, se concentraram em combater a violência policial historicamente vivida por esta população e, para além disso, elaboraram estratégias para combater as desigualdades sociais e péssimas condições de trabalho do homem negro e da mulher negra.

Ainda além das pautas acima, os militantes e intelectuais negros do período reivindicaram políticas públicas que fossem executados no espaço escolar, tais como a inclusão da História da África e da população negra nos currículos e, no decorrer da década 1990, os documentos educacionais como a Lei de Diretrizes e Base da Educação Nacional, 9394 de 1996 e os Parâmetros Curriculares Nacionais de 1997 atenderam em parte as solicitações do movimento negro. Entretanto, somente em 2003, com a aprovação da Lei 10.639/03, a demanda por políticas educacionais efetivas voltadas para pessoas negras foram sancionadas, com o consequente questionamento das relações assimétricas de poder entre os grupos formadores da identidade nacional.

A aprovação da referida lei impôs uma série de desafios para a formação docente, tais como: pensar as relações de poder que perpassam a organização dos conteúdos no currículo escolar; a necessidade de uma maior atenção aos cursos de formação inicial e continuada que considerasse as relações raciais como um dos mobilizadores da estruturação educacional brasileira; a organização de materiais didáticos-pedagógicas que auxiliassem os docentes na efetivação da Lei em sala de aula 
e, especialmente, a mudança de paradigmas na mentalidade do/a professor/a ao passar a reconhecer o racismo como um elemento estrutural presente na sociedade do Brasil.

Apesar de reconhecermos os avanços na aplicabilidade do ensino da História e Cultura afro-brasileira e africana nas salas de aula nos últimos dezessete anos, pesquisas recentes, como as realizadas por Gomes (2013), Gonçalves (2018), Felipe e Moreira (2019), demonstram que, no processo de implementação da referida lei, é possível observar que muitas escolas se orientam, no momento de lecionar os conteúdos programáticos pertinentes à História e Cultura afro-brasileira, por representações estereotipadas do continente africano, bem como da população afro-brasileira, enquanto outras reservam as últimas semanas do mês de novembro para trabalhar com tais conteúdos e, ambas, fomentam e reafirmam representações equivocadas, quando não estereotipadas, da população africana, comportamentos e atitudes que, inversamente ao objetivado, acabam por reforçar ainda mais o racismo em nosso país.

Com intuito de colaborar com a prática pedagógica de docentes que atuam na rede pública de ensino do Paraná o Núcleo de Estudos Interdisciplinares Afro-Brasileiros da Universidade Estadual de Maringá - Paraná (NEIAB/UEM) em parceria com a Secretaria da Ciência, Tecnologia e Ensino Superior do Paraná (SETI), por meio do seu Programa Universidade Sem Fronteiras, e com os Núcleos Regionais de Educação de Maringá e Cianorte (NRE/Maringá e NRE/Cianorte), ministramos ${ }^{1}$ o curso de extensão ${ }^{2}$ intitulado Ações de promoção à formação de professoras e professores para o ensino de História e Cultura afro-brasileira na Educação Básica.

O curso foi organizado em seis encontros, cada um com um tema gerador: O primeiro encontro teve como tema '15 anos da Lei 10.639/2003: Temas, conceitos e dilemas'; O segundo encontro teve como tema 'Desigualdade Social e Racismo no Brasil'; já o tema do terceiro encontro foi 'História da África e do povo negro no Brasil'; o quarto encontro 'A Lei 10.639/2003 e os Direitos Humanos'; O quinto encontro teve como tema 'Educação, geração de renda e afroempreendorismo' e, no último encontro, o tema foi 'A escola como um campo de poder e o ensino de História e Cultura afro-brasileiro e africana'. Todos os encontros foram ministrados entre os meses de outubro de 2018 e setembro de 2019, cada um com 8 horas de duração, perfazendo uma carga horária total de 48 horas.

O curso contou com 132 participantes. Apesar de ser aberto a professores e professoras de todos os níveis e disciplinas, desde que estivessem vinculados aos NRE/Cianorte e NRE/ Maringá, percebemos um predomínio dos docentes que atuavam em sala de aula com a disciplina de História.

\footnotetext{
${ }^{1} \mathrm{O}$ curso, assim como este artigo, foi elaborado através do trabalho de uma equipe interdisciplinar do qual destacamos atuação singular do Prof. Dr. Delton Felipe Aparecido e da graduanda em História Ana Paula Herrera de Souza.

2 O Curso de extensão foi registrado sob protocolo 3173/2019 junto à Divisão de Extensão e Cultura da Universidade Estadual de Maringá Paraná
} 
Acreditamos que isso pode ser explicado pelas atuais configurações deste componente curricular, que entende que "os sujeitos sociais, sendo históricos, são, também, culturais. Esta constatação indica que é necessário repensar a nossa escola e os processos de formação dos docentes, rompendo com as práticas seletivas, fragmentadas, corporativistas, sexistas e racistas ainda existentes" (GOMES e SILVA, 2006, p.25).

Devido à quantidade de questionamentos, dúvidas e problematizações que surgiram no decorrer da extensão, optamos por, no presente artigo, tratarmos das intervenções pedagógicas realizadas com os docentes no terceiro encontro, que teve como foco retratar a importância do continente africano para que se compreendesse a situação da população negra no Brasil e apresentar práticas docentes que permitam problematizar e descontruir os estereótipos referentes às Áfricas nas disciplinas escolares.

O curso teve caráter de intervenção pedagógica na formação continuada dos docentes da educação básica e, durante os encontros com os professores e professoras, utilizamos notas de campo que intitulamos de Diário de Bordo. Essa metodologia foi adotada por permitir relatar as impressões do pesquisador/palestrante diante de várias discussões feitas no decorrer do processo de intervenção. As notas de campo, com base em Bogdan e Biklen (1994), referem-se às conversas obtidas entre os sujeitos, assim como o que os próprios sujeitos disseram ao pesquisador em particular.

$\mathrm{Na}$ elaboração deste artigo, priorizamos as narrativas dos docentes contidas no Diário de Bordo, já que, nessas narrativas, os sujeitos da pesquisa se expressaram livremente, permitindo que suas representações sobre o mundo, mesmo que de forma provisória, viessem à tona. Concentraremos nossas reflexões nos temas, questionamentos e encaminhamentos pedagógicos referentes ao terceiro encontro, que teve como finalidade discutir a importância do ensino de História da África para pensarmos a presente situação social da população negra no Brasil.

\section{Por que ensinar história da África nas escolas brasileiras?}

Ao discutirmos a História da África na historiografia brasileira, observa-se como um ponto comum tanto para os historiadores quanto para os intelectuais das diferentes áreas de saber, afirmar que as narrativas propagadas sobre o continente africano no Brasil, ainda tem como base o ponto de vista do europeu colonizador, seja pelo viés religioso, como a crença de que os africanos são descendentes de um povo amaldiçoado por "Deus", ou pelo viés clínico-biológico, como uma perspectiva eugenista recorrente no decorrer do século XIX, que postulou que os povos africanos eram biologicamente inferiores aos europeus. 
Para compreendermos de uma forma sintética as narrativas estereotipadas do sujeito africano, ou melhor, dos sujeitos africanos, visto que estamos tratando de uma diversidade de povos que se identificavam com sua realidade local, como grupo étnico e/ou povo e não como uma identidade continental como geralmente vemos nos estudos da atualidade, recorremos às formulações de Hernandez (2005), Serrano e Waldman (2007); Felipe (2010) que, ao realizarem uma análise sobre a historiografia do continente, afirmam que na Antiguidade, por exemplo, os romanos chamavam todos aqueles que não estavam em seu território, ou não falavam uma língua latina e, posteriormente, não professavam o cristianismo, de berbere, o que daria origem ao termo bárbaro. Porém, no decorrer da história, esse termo passou a ser compreendido como sinônimo de selvagens e não civilizados.

Organizar um encontro de formação de docentes que objetivava demonstrar como parte do racismo vivenciado pela população negra brasileira está ancorada nas narrativas estereotipadas e nos preconceitos que os povos africanos sofrem e sofreram ao longo da história, perpassou, necessariamente, por fazer uma breve síntese da História das Áfricas e o eurocentrismo, o que implicou também em retratar a amplitude dos processos sociais, políticos, econômicos e culturais que configuram o continente africano, desde a Antiguidade até os dias atuais. A África tem uma vasta dimensão territorial e é, extremamente, diversificada.

O ensino da História da África na atualidade implica, necessariamente, na compreensão histórica das diferentes regiões do continente, no reconhecimento das mais variadas manifestações e organizações sociais a partir de suas dinâmicas internas e das relações com outros povos, como os orientais, europeus e americanos. Essa multiplicidade de vivências históricas e sociais é tão importante no ensino de História da África que autores como Souza e Felipe (2019 p.57) preferem utilizar o conceito de Áfricas para se referir ao continente.

É preciso admitir que a amplitude que tem a História e os processos culturais dos povos africanos, gera um grande desafio que é: qual História deveria ser trabalhada na educação brasileira? Cunha Junior (2006), argumenta que, a História africana que deve ser priorizada é aquela que possibilita a compreensão do Brasil, aquela que ajuda a explicar os aportes significativos dos africanos diaspóricos para a construção da sociedade brasileira e permite a desconstrução dos inúmeros estereótipos e preconceitos vivenciados pelos homens e mulheres negras.

Com relação ao trabalho que desenvolvemos com os cursistas, reconhecemos que seria e que é necessária a construção de uma História da África que considere a sua dinâmica interna e os processos de sociabilidades dentro do continente e suas diversas regiões. Porém, devido à carga horária do encontro, optamos, por retratar uma História da África condicionada à ideia de 
ancestralidade por compreendermos que é um direito de memória da população brasileira, sobretudo das pessoas negras. Por isso, no decorrer do encontro, priorizamos tratar os aspectos das Áfricas que nos permitissem pensar a situação histórica da população afrodiaspórica no Brasil e, a partir daí, inserir explicações sobre como os cursistas poderiam trabalhar conteúdos e/ou temas referentes a este continente em sua sala de aula.

Após fazer uma breve síntese sobre as narrativas concernentes à História Africana no Brasil, voltamos os nossos esforços didático-pedagógicos para responder à questão que intitula a seção. Para isto, indicamos aos docentes a leitura do livro infanto-juvenil "Bia na África", de Ricardo Dreguer (2016). Com o intuito de indicar a literatura infanto-juvenil para os docentes, decidimos utilizá-la como recurso didático pedagógico para contextualizar e problematizar as informações sobre o continente africano e as narrativas estereotipadas sobre essa população, que ainda circulam no tecido nacional. Esta estratégia se mostrou extremamente eficaz, visto que os cursistas fizeram diversos questionamentos e reflexões tendo como referência o material indicado. Não podemos esquecer de mencionar que outro fator que nos levou a escolher o livro mencionado acima, é que ele é protagonizado por uma menina negra, gerando representatividade aos milhares discentes afro-brasileiros que estão em nossas escolas, querendo aprender sobre si e muitas vezes não conseguindo ter essa representatividade nos recursos didáticos pedagógicos usualmente utilizados em sala de aula.

O livro Bia na África (2006) foi escrito por Ricardo Dreguer, Bacharel e licenciado em História pela Universidade de São Paulo (USP), e autor de livros didáticos e para didáticos voltados ao Ensino Fundamental. Fazem parte da mesma coleção a que pertence o livro citado, 'Bia na América'; 'Bia na Ásia' e, tratando de uma temática próxima à de 'Bia na África', Dreguer escreveu também 'Kiese: A História de um africano no Brasil'. O livro cuja leitura indicamos aos participantes narra a história de Bia, uma menina negra de oito anos, que em um belo dia recebe a notícia de que sua mãe, uma mulher negra, havia sido convidada para trabalhar na embaixada brasileira em Angola. Ao receber a informação, Bia fica preocupada com o que encontrarão no continente africano, por conta do que ela tinha ouvido no Brasil sobre os países do continente africano. Ao expor para a mãe os seus receios, esta resolve, antes de começar a trabalhar em Angola, explicar para Bia as semelhanças históricas e sociais de diversos países africanos com o Brasil. Para isso, antes de se mudar para Angola com a filha, ela organiza uma viagem passando por diferentes países africanos como Egito, Quênia, Mali, Congo, Zimbábue e Sudão. No decorrer da viagem Bia desconstrói a visão que tinha sobre o continente africano, pois, assim como boa parte dos brasileiros, a menina, mesmo sendo negra, tinha uma visão estereotipada do continente de seus 
ancestrais e imaginava que as Áfricas eram selvagens e permeadas pela fome e pobreza, como podemos perceber no trecho que destacamos abaixo:

\footnotetext{
No dia seguinte, voltei a conversar com minha mãe:

- Com tanto lugar para trabalhar, por que você aceitou ir para a África?

- Por que lá estão muitas das raízes da história do Brasil. E também as origens de nossos antepassados.

Eu sabia que tinha a ver com essa história de raízes. Minha mãe adorava contar que os nossos antepassados vieram da África para o Brasil como 'escravos'. E que lutaram muito para conquistar a liberdade. É por isso que minha mãe diz que devemos ter muito orgulho de sermos negras.

- Então, se a gente for morar na África, vamos fazer o caminho inverso dos nossos antepassados. (DREGUER, 2016, P.12)
}

O trecho acima, foi um dos que destacamos para os cursistas, com intuito de que eles percebessem que discutir a história da população negra no Brasil, implica, necessariamente, em discutir aspectos sócio-históricos das Áfricas. Como ressalta a mãe de Bia, o continente africano é fundamental para pensar as raízes históricas do Brasil, visto que mais da metade da população nacional reconhece sua ancestralidade africana. Este percentual torna o Brasil o segundo país mais negro do mundo, superado somente pela Nigéria que, por sua vez, é o país mais populoso do continente africano (SOUZA E FELIPE, 2019). Portanto, o que buscamos deixar claro para os docentes é que o alto percentual de pessoas que se reconhecem negras no Brasil já é um ótimo motivo para a inserção de temas e conteúdos referentes à História das Áfricas no currículo escolar brasileiro.

Foi nesse momento do encontro, que uma professora questionou que, se continente africano é tão importante para entendermos a História do Brasil, por que temos poucas informações sobre ele nos currículos escolares ${ }^{3}$ ? Explicamos à docente e aos demais presentes que, devido a um currículo escolar que tem como base uma perspectiva eurocêntrica, à história e cultura africanas não foi dada a devida atenção nos currículos das escolas brasileiras, o que levou à construção de uma história parcial, distorcida e racista que, por sua vez, fez com que população negra não se visse representada no espaço escolar. Informamos que há autores, como Mattos (2003), que argumentam que, sem o ensino profundo da História Africana, temos uma História do Brasil parcial, limitada, enviesada e que promove o racismo estrutural, que afeta o cotidiano tanto das pessoas negras como das não negras, em nosso tecido social. Conforme se nota, é imprescindível que a História do continente africano esteja presente nos currículos escolares do Brasil. Ela é essencial tanto para explicar a História da Humanidade e o povoamento do mundo,

\footnotetext{
${ }^{3}$ As falas dos cursistas estão sem a identificação da autoria, pois a nossa preocupação não era registrar quem, mas o que foi dito, conforme a metodologia de coleta de dados que utilizamos.
} 
quanto para o entendimento da História Econômica do mundo oriental e ocidental, bem como para visibilizar as diversas situações de racismo por que passam as pessoas negras.

A partir da explicação acima, passamos a chamar a atenção dos docentes para a premissa de que, para pensar e trabalhar a História da África no Brasil, iríamos priorizar as semelhanças geográficas, sociais e culturais entre essas duas regiões, que são explicáveis devido ao intercâmbio cultural gerado pela escravização capitalista a partir do século XVI e também porque as duas regiões já fizeram parte da mesma porção de terra no período da Pangeia. Há também que se considerar que o Brasil e as Áfricas apresentam muitas experiências humanas similares.

Explanamos também sobre outros fatores que fazem com que a História do continente africano seja de fundamental importância para o enriquecimento dos currículos escolares no Brasil, uma vez que ela é essencial para explicar a História da Humanidade e o povoamento do mundo bem como a História Econômica, tanto ocidental quanto oriental. Lembramos que, no mundo ocidental, os povos africanos foram de fundamental importância para o desenvolvimento do capitalismo e dos processos que o potencializaram como, por exemplo a Revolução Industrial (XVIII), uma vez que foram esses homens e mulheres das Áfricas que trabalharam nas inúmeras lavouras que alimentaram as indústrias têxteis inglesas, como as de algodão nas colônias britânicas da América do Norte (HERNANDEZ, 2005).

Foi nesse momento então que um docente, erguendo a mão, disse que a escravização dos povos africanos também deixou marcas sociais e culturais na realidade brasileira, pois ela transplantou para o Brasil, por mais de três séculos e meio, diversas manifestações culturais do continente africano. No entanto ele demonstrou interesse em saber se é verdade que os africanos escravizavam os próprios africanos? Respondemos a essa dúvida do docente esclarecendo que a problematização de seu questionamento necessariamente perpassa a escravidão e suas características e, assim, consideramos importante desenvolvê-la como um conceito que só pode ser entendido em um determinado tempo e espaço, pois essa explicação está diretamente conectada com a sociedade em que está inserida.

A escravidão, como fenômeno histórico, esteve presente na trajetória da humanidade desde a fase final do Neolítico (8000 a.c a 5000 a.c) até períodos mais recentes, como consta em trabalhos acadêmicos e na literatura especializada. No debate historiográfico, há dificuldades em se obter um consenso quanto à origem da escravidão, tendo sido produzidas variadas hipóteses. O que há em consenso é acerca da etimologia de "escravo" que, de acordo com Cunha (1986), deriva-se do latim medieval "sclavus", cuja origem primitiva vem de eslavos, povos que viviam na atual Europa central 
e oriental, e que, no decorrer dos séculos VIII e IX, foram aprisionados por Carlos Magno e seus sucessores, tornando-se cativos.

Apesar da dificuldade de pesquisar a origem da escravidão como prática social, conceitualmente, ela está vinculada ao direito de propriedade de um indivíduo sobre outro, de forma violenta ou não (SILVA, 2003). Como resultado dessas diversas formas de escravização, surge o escravo, indivíduo transformado em cativo, que vive em estado de servidão. No caso da escravidão aplicada à população africana, o tipo mais conhecido, o/a negro/a africano/a era visto/a como uma propriedade, isto é, como coisa e isento/a dos valores e direitos atribuídos àqueles/as considerados/as seres humanos. Este fenômeno, responsável pelo funcionamento e eficácia do colonialismo, ocorreu em diversos territórios explorados pelos portugueses, espanhóis e ingleses, no período que vai do século XVI ao XIX. Este tipo de escravidão estava vinculado a uma relação de dominador e dominado, e seu objetivo era a produção e distribuição de produtos para uma economia mundial, na qual o escravo africano era o mecanismo essencial para o funcionamento dessa rede comercial.

Nas sociedades escravocratas, o trabalho assalariado era raro e o trabalho escravo era a regra sempre que uma tarefa fosse grande demais para que uma família a conduzisse, sem auxílio. A regra se estendia da agricultura à manufatura e à mineração, e algumas vezes, até mesmo ao comércio e às finanças.

Na África, descreve Lovejoy (2002), a escravidão passou por essa transformação em épocas diferentes e em diferentes proporções. A transformação foi resultado da consolidação de um modo de produção baseado na escravidão, aqui enfatizando a relação entre a organização social, o processo produtivo e os meios pelos quais esta relação foi mantida. De fato, a escravidão era uma atividade que já existia na África antes da chegada dos colonizadores europeus ao continente, por volta do século XV, mas, devemos lembrar que, devido as condições sociais e históricas, podemos categorizar os tipos de escravidão em pelo menos três:

$\checkmark$ Escravidão doméstica: baseada em estruturas familiares, essa escravidão operava em forma de punições que eram exercidas por conta de dívidas ou até mesmo crimes cometidos em determinada região;

$\checkmark$ Escravidão islâmica: A partir da disseminação do islamismo, por volta do século VIII, os árabes se deslocaram por meio de acordos comerciais com o intuito de islamizar os ditos "infiéis". Assim, apesar dos escravizados serem deslocados para o Oriente Médio, se permitia a volta deles ao país de origem e a liberdade dos seus primeiros descendentes;

$\checkmark$ Escravidão capitalista: sem diferenciação de gênero ou faixa etária, homens e mulheres negros africanos eram tidos como moedas de troca, sofrendo retirada cruel de sua terra natal e sem direito à volta, se tornando então, nas colônias, principalmente nas Américas, instrumentos vivos de trabalho (LOVEJOY, 2002). 
Quando tratamos de questionar se os negros - africanos - escravizavam a si mesmos, estamos falando sobre a escravidão que acontecia no continente africano e de suas características específicas, o que configurava uma escravidão de caráter doméstico. Devemos entender que, na África, a cultura é um fator primordial, ainda mais importante é considerarmos que os povos, grupos ou conjuntos familiares eram organizados por etnias - um conceito polivalente - que constrói a identidade de um indivíduo tomando como base parentesco, religião, língua, território compartilhado e nacionalidade, para além da aparência física (SANTOS; PALOMARES; NORMANDO; QUINTÃO, 2010).

Como Lovejoy (2002) afirma, a escravidão que existia nas sociedades africanas, não era uma forma de escravidão comum, pois não mudava a formação social do local. A escravidão era uma das várias relações de dependência, bem como um instrumento de potencialização do número de pessoas que exerciam a mesma função, aumentando, então, o poder político do indivíduo ou do grupo. Frisamos que é errado colocar a forma de escravidão que acontecia nas sociedades africanas como mais leve ou mais fraca, mas devemos levar em consideração que ela se diferencia da escravidão que aconteceu com os povos africanos pelas mãos do colonizador europeu. Uma vez que esta escravidão promoveu a retirada dos mesmos de sua nação, ferindo sua cultura e os colocando em condição de inumanidade e sem direito a nada que representasse a dignidade humana do sujeito escravizado nas colônias.

Aproveitamos para dizer aos cursistas que, ao ouvir o questionamento acima em sala de aula, caberá ao docente explicar que a escravidão é um conceito histórico e que a aplicabilidade desse fenômeno no continente africano, tem variações de acordo com as condições sociais internas, além de estar sujeito às intervenções externas. Ademais, é fundamental que o/a professor/a faça/m com que os/as alunos/as entendam que a manutenção da afirmação "que africanos escravizavam outros africanos", sem a devida contextualização histórica, é uma das formas de enredar esses grupos em discurso de barbárie e não civilidade, uma estratégia comum, na perspectiva eurocêntrica, para inferiorizar os povos não europeus, além de funcionar como justificativa risória para os processos de violência e dominação sofridos pela população negra sob o regime de escravidão capitalista.

O processo de escravização que ocorria na África era um acontecimento que variava de acordo com a região, cultura e grupos sociais envolvidos nesse processo. É necessária uma análise do contexto histórico e das características específicas, devido à enorme complexidade social, política e cultural. Temos que levar em consideração a relação que existia entre a escravidão e as questões de terra, pois o vasto território que constitui o continente, levava a mão-de-obra a ser 
uma questão essencial para o desenvolvimento econômico-social. Assim, a quantidade de escravos por família determinava sua riqueza e seu posicionamento social, significando fortalecimento político para o grupo étnico que possuía os escravos (LOVEJOY, 2002).

Pensamos então que, para a construção de caminhos pedagógicos voltados ao ensino de História das Áfricas demandará articular todo o conhecimento que veio com a população africana em situação de escravidão, com a realidade social brasileira, como os saberes e as práticas sociais que interligam as duas regiões, histórica e socialmente falando. Ao fazer isso, diferentemente das narrativas eurocêntricas que dão conta de que os africanos do passado, e até mesmo do presente, são selvagens e atrasados, reconstruiremos narrativas em sala de aula nas quais os ancestrais da presente população negra, que aqui aportaram em situação de escravidão, vindos de diversas regiões do continente africano, tinham vasto conhecimento de técnicas agrícolas, metalúrgicas e de tecelagem, por exemplo.

Os conhecimentos advindos dos povos das Áfricas no Brasil, foram cruciais para formação nacional, pois estiveram e ainda estão presentes em diversas áreas, o que permite que consideremos que esses saberes devem integrar também as mais variadas disciplinas escolares. Lembrando, é claro, que, na maioria das vezes, os temas e/ou conteúdos referentes a esse continente devem ser trabalhados em uma perspectiva interdisciplinar para dar conta da complexidade de sua realidade social.

No ensino da língua portuguesa é essencial aprendermos na escola que o português escrito e falado no Brasil hoje é composto, em seu DNA, pelas Áfricas. Como demonstram Barros e Cavalcanti (2006), a invisibilidade das referências africanas no universo da língua portuguesa, se por um lado nos remete à incorporação dessas palavras em nosso cotidiano, como xixi, meleca babaca, brucutu, coroca, sacana, fuleiro, é preciso também considerar as hierarquizações no processo de constituição da língua portuguesa no Brasil, que em sua base formal privilegia a Europa em detrimento da África e dos povos indígenas.

Outro encaminhamento pedagógico que pode ser adotado pelos docentes de língua portuguesa é a utilização da produção literária africana e a literatura negra em sua aula. Essa estratégia permite que os/as alunos/os tenham contato com uma diversidade de narrativas sobre a história e cultura da África, desconstruindo a visão estereotipada e eurocêntrica que possam ter do continente. Além de propiciar a consciência de um "existir negro" e de uma história comum engendrada pela afrodescendência. A "literatura negra" circunscreve um sentimento de pertença, arraigado na própria história dos africanos no Brasil (BERND, 1992, P.27). 
Para os docentes de Matemática/Física/Química, é essencial tratar a influência de pensadores africanos na constituição histórica de suas disciplinas. Por exemplo, é fundamental desconstruirmos a mentalidade de que as ideias matemáticas, que são essenciais para os três componentes curriculares mencionados, venham, essencialmente, da Grécia Antiga e dos Árabes. É preciso reafirmar as importantes contribuições de diversos países africanos, como o Antigo Egito. É lógico que isso demanda romper com a ideia propositadamente equivocada de falar no Egito como se fosse uma civilização separada do continente africano. As ideias matemáticas oriundas de culturas africanas na educação matemática no Brasil, na perspectiva das leis de combate ao racismo, de promoção da diversidade cultural e, principalmente, a valorização das contribuições africanas para com a cultura brasileira, constituem um desafio que precisa ser aceito pelos docentes que têm a matemática como base das suas disciplinas (GERDES, 2012).

A Etnomatemática é uma outra área que pode colaborar, decisivamente, para trabalharmos com a cultura africana em sala de aula. Por ter como finalidade o reconhecimento da cultura plural, responsável pela constituição do país, e que deve sim, ser levada em consideração para a elaboração que responda aos anseios de sua população. Por exemplo, os africanos mesmo sendo visto como inferiores pelos europeus no processo de colonização, em seus assentamentos visualizavam arranjos matemáticos complicados, hoje conhecidos como fractais enquanto os povos da Europa por sua vez utilizavam arranjos euclidianos, onde se observavam retas paralelas e formas geométricas regulares, que são arranjos matemáticos mais simples. Isto demonstra que essa inferioridade era mais uma estratégia discursiva de colonização do que uma realidade de fato (SILVA E ZANLORENZI, 2015). Não podemos deixar de mencionar os diversos jogos de origem africana, como por exemplo, os da família do Mancala, que pode ser utilizado em sala de aula para estimular conhecimento de aspectos dessa cultura, além de favorecer o raciocínio lógicomatemático utilizado nas disciplinas de Química e Física.

Quanto aos professores/as de Geografia/História/Sociologia/Antropologia/Artes/ Filosofia, dada a singularidade de cada um desses componentes curriculares, que fazem parte das ciências da humanidade, os mesmos são essenciais para o entendimento da situação sócio geográfica, como dos processos de exploração das riquezas naturais do território africano e a situação de pobreza em que povos da África foram colocados no decorrer da história. Para além disso, essas disciplinas colaboram para o entendimento dos fluxos migratórios dentro do continente africano e a necessária compreensão dos processos de sociabilidade e de trocas culturais resultantes desses movimentos humanos. 
Um exemplo que destacamos é a contribuição da geografia e seus estudos das três grandes bacias hidrográficas daquela região (Nilo, Mali e Zambeze) que permitem o entendimento dos processos de trocas técnicas, de culturas e de conhecimentos dos diversos povos africanos quem devido a diáspora causada pela escravidão, trouxeram grande parte desses saberes para o Brasil e, hoje, se configuram como conhecimentos essenciais para a compreensão da cultura nacional (VISENTINI; RIBEIRO, PEREIRA, 2012). Podemos ainda ressaltar que só entenderemos a importância das trocas entre africanos e, depois, como elas influenciaram o Brasil, a partir do conhecimento da visão de mundo daqueles povos (Filosofia), seus aspectos históricos (História), organizações sociais (Sociologia), produções culturais (Artes) e singulares da sua interação com o mundo (Antropologia).

Aos docentes de Biologia/Ciências, há uma série de conteúdos que podem ser relacionados com as Áfricas e a população negra no Brasil. No entanto, um dos mais significativos para desconstruir os estereótipos de que africanos são biologicamente inferiores aos europeus e seus descendentes, é a discussão que tem como base o conceito de raça. O termo raça, do ponto de vista biológico, não tem adequada aplicação na espécie humana. Isto porque qualquer conjunto significativo de características que se considere para tentar incluir os seres humanos em uma classificação cai em uma situação onde não se consegue delimitar grupos para constituir uma subespécie ou diferenciar raças. É o fenótipo que tem sido usado, historicamente, como meio para classificar e organizar os indivíduos de uma população, que nos permite fazer essa discussão numa dimensão social. Além disso, os estudos sobre evolução e genética abrem caminhos para pensar os estereótipos vivenciados pelos povos africanos e os seus diaspóricos (STELLING, 2007).

\section{Considerações}

Ao nos encaminharmos para o encerramento do encontro com os docentes, informamos não haver mais, dentro do cronograma dos Encontros, tempo disponível para novas propostas pedagógicas, porém, na qualidade de pesquisadores do NEIAB/UEM cujo objetivo é promover e estimular estudos sobre as questões e as relações raciais no processo educacional, permaneceríamos à disposição para outras conversas e indicações para a efetivação de livros, textos e artigos que possibilitassem a elaboração de práticas pedagógicas para o ensino de temas/conteúdos sobre as Áfricas e suas relações com o Brasil.

O ensino da História do continente africano e suas relações com o Brasil devem ser trabalhadas na escola a partir de diferentes matrizes de pensamento. Somente assim poderemos descobrir uma África que se contrapõe à visão eurocêntrica. Se continuarmos com práticas 
pedagógicas que tratam o continente africano de forma estereotipada, vamos continuar desvalorizando o povo negro e os conhecimentos oferecidos pelas Áfricas na formação de nosso país. No entanto, se conseguirmos construir caminhos pedagógicos que valorizem a diversidade existente no continente africano e nos ofereça elementos para perceber a importância das Áfricas no tecido nacional, permitiremos que todas as pessoas reconheçam o papel fundamental das Áfricas e africanos na História do Brasil e teremos crianças negras orgulhosas de sua ancestralidade em uma sala de aula que não reduza seus antepassados somente à escravidão.

\section{Referências}

BARROS, Rachel Rocha de Almeida; CAVALCANTI, B. C. O lugar social das palavras africanas no português do Brasil. Kulá-Kulé: visibilidades negras. Maceió: EDUFAL, 2006.

BERND, Zilá. Poesia negra brasileira - Antologia. Porto Alegre: AGE/IEL/IGEL, 1992.

BOGDAN, Roberto C.; BIKLEN, Sari Knopp. Investigação qualitativa em educação. Porto: Porto Editora, 1994.

BRASIL. Lei $n^{\circ} 10.639$, de 9 de janeiro de 2003. Altera a Lei $n^{\circ} 9.394$, de 20 de dezembro de 1996, que estabelece as diretrizes e bases da educação nacional, para incluir no currículo oficial da rede de ensino a obrigatoriedade da temática "História e Cultura Afro-Brasileira", e dá outras providências. Diário Oficial da União, Brasília, DF, 10 jan. 2003.

BRASIL. Ministério da Educação. Diretrizes Curriculares Nacionais para a Educação das Relações ÉtnicoRaciais e para o Ensino de História e Cultura Afro-Brasileira e Africana. Brasília, 2004.

BRASIL. Parecer No. CNE/CP 003/2004 do Conselho Nacional de Educação. Diretrizes Curriculares Nacionais para a Educação étnico-raciais e para a História e Cultura Afro-Brasileira e Africana. Disponível em: http://portal.mec.gov.br/cne/arquivos/pdf/003.pdf; acesso em 21. abr. 2019.

BRASIL. Secretaria de Educação Fundamental. Parâmetros curriculares nacionais: introdução aos parâmetros curriculares nacionais / Secretaria de Educação Fundamental. - Brasília: MEC/SEF, 1997.

CUNHA, Antônio Geraldo da. Dicionário Etimológico da Lingua Portuguesa. 2 Ed. Rio de Janeiro: Editora Nova Fronteira, 1986.

DREGUER, Ricardo. Bia Na África. 2. Ed, São Paulo: Moderna, 2016.

FELIPE, Delton Aparecido; MOREIRA, Liege Torresan Estratégias para o ensino de história e cultura afro-brasileira. Revista Africa e Africanidades, v. XII, p. 1-13, 2019.

Disponível em: https:/ / africaeafricanidades.online/documentos/0020052019.pdf

GERDES, P. Ideias matemáticas originárias da África e a educação matemática no Brasil. Revista Tópicos Educacionais, p. 139-158, 2012.

GOMES, Nilma Lino; SILVA, Petronilha Beatriz Gomes e (orgs). Experiências étnico-culturais para a formação de professores. 2.ed. Belo Horizonte: Autêntica, 2006. 
GOMES, Nilma Lino. Panorama de Implementação da Lei nº10.639/2003: Contribuições da Pesquisa Práticas Pedagógicas de Trabalho com Relações Étnico-raciais na Escola. In: SILVA, Tatiana Dias; GOES, Fernanda Lira. Igualdade Racial no Brasil: Reflexões no Ano Internacional dos Afrodescendentes. Brasileia: Ipea, 2013.

GONÇALVES, Rosângela Cristina. Quinze anos da Lei 10.639/03 - avanços e retrocessos. RIDPHE_R Revista Iberoamericana Do Patrimônio Histórico-Educativo, 4(2), 2018 pp. 434439.

HERNANDEZ, Leila leite. A África na sala de aula. São Paulo: Selo Negro, 2005.

LOVEJOY, Paul. A Escravidão na África - Uma História de suas Transformações. Rio de Janeiro: Civilização Brasileira, 2002.

MATTOS, Hebe Maria. O ensino de História e a luta contra a discriminação racial no Brasil. In: ABREU, Martha; SOIHET, Rachel (Org.). Ensino de História: conceitos, temáticas e metodologia. Rio de Janeiro: Casa da Palavra, 2003, p. 127-136.

MOREIRA, L. T. ;FELIPE, Delton Aparecido. Direitos humanos e as relações étnico-raciais no espaço escolar. In: PRIORI, Angelo; FELIPE, Delton Aparecido; PEREIRA, Márcio José.

(Org.). Conversas sobre direitos humanos e práticas educativas no espaço escolar. 1ed. Maringá - Paraná: Edições Diálogos, 2019, v. 1, p. 78-87.

MUNANGA, Kabengele. Rediscutindo a mestiçagem no Brasil: identidade nacional versus identidade negra. 3ed. Belo Horizonte: Autêntica, 2008.

SANTOS, Diego Junior da Silva; PALOMARES, Nathália Barbosa; NORMANDO, David; QUINTÃO, Cátia Cardoso Abdo. Raça versus etnia: diferenciar para melhor aplicar. Dental Press J Orthod. vol.15, no.3, p. 121-124, 2010.

SANTOS, Diego Junior da Silva; PALOMARES, Nathália Barbosa; NORMANDO, David; QUINTÃO, Cátia Cardoso Abdo. Raça versus etnia: diferenciar para melhor aplicar. Dental Press J Orthod. vol.15, no.3, p. 121-124, 2010.

SERRANO, Carlos; WALDMAN, Mauricio. Memórias d'África: a temática africana em sala de aula. São Paulo: Cortez, 2007.

SILVA, Alberto da Costa e. A Africa explicada aos meus filhos. Rio de Janeiro: Agir, 2008.

SILVA, Alberto da Costa e. A manilha e o libambo. A escravidão na África de 1500 a 1700. Rio de Janeiro: Nova Fronteira/Ed. UFRJ, 2003.

SILVA, Ronaldo Tomaz de Andrade; ZANLORENZI, Marcos Aurélio. Etnomatemática e alguns algoritmos africanos: articulando questões étnico-raciais e conteúdo de matemática. Ebrapem, ufjf, 2015

SOUZA, Ana. Paula Herrera; FELIPE, Delton Aparecido . História da África e do povo negro no Brasil: construção de caminhos pedagógicos. In: Felipe, Delton Aparecido. (Org.). Educação para as relações étnico-raciais: estratégias para ensino de história e cultura afro-brasileira. 1ed.Maringá: Mondrian, 2019, v. 1, p. 55-74. 
STELLING, Luiz Felipe Peçanha. "Raças humanas" e raças biológicas em livros didáticos de Biologia de ensino médio. Tese de Doutorado. Dissertação (Mestrado em Educação), Departamento de Educação, Universidade Federal Fluminense, Rio de Janeiro. 2007

VISENTINI, Paulo Fagundes; RIBEIRO, Luiz Dario Teixeira; PEREIRA, Analúcia Danilevicz. História da Africa e dos africanos. Editora Vozes Limitada, 2012. 